\title{
Idiopathic acute eosinophilic pneumonia
}

\author{
Matthew Pizzuto, Matthew Seychell, Brendan Caruana Montaldo, Adrian Mizzi
}

Department of Medicine, Mater Dei Hospital, Msida, Malta

\section{Correspondence to} Dr Matthew Pizzuto, matthew.a.pizzuto@gov.mt

MP and MS are joint-first authors and equally contributed to this work.

Accepted 26 August 2019
Check for updates

(c) BMJ Publishing Group Limited 2019. No commercial re-use. See rights and permissions. Published by BMJ.

\begin{tabular}{|l|}
\hline To cite: Pizzuto M, \\
Seychell M, \\
Caruana Montaldo B, \\
et al. BMJ Case Rep \\
2019;12:e231095. \\
doi:10.1136/bcr-2019- \\
231095 \\
\hline
\end{tabular}

\section{SUMMARY}

A 44-year-old asthmatic male patient presented to the health centre with a 3-week history of coryzal symptoms, persistent productive sputum and shortness of breath. The chest X-ray (CXR) revealed symmetrical, perihilar airspace shadowed with peribronchial cuffing and bilateral reticular markings. The patient did not improve despite treatment, and hence a high resolution CT (HRCT) scan of the thorax was recommended. The HRCT showed smooth interlobular septal thickening, central perihilar soft tissue thickening and patches of ground glass changes. Both the CXR and HRCT findings, along with the symptoms and eosinophilia counts, were suggestive of idiopathic acute eosinophilic pneumonia (IAEP) which was confirmed on bronchoalveolar lavage. The patient was successfully treated with steroids. This case highlights the symptoms, diagnosis, management and treatment of IAEP. A rapid diagnosis of this rare disease is essential since it can be completely cured with correct management but can be fatal if left untreated. Once properly treated, this disease does not recur.

\section{BACKGROUND}

Eosinophilic lung diseases are a wide range of diseases and conditions which are characterised by an increase in the number of eosinophils in the lung tissue. A normal lung will only have a small percentage $(<2 \%)$ of eosinophils present on bronchoalveolar lavage (BAL). This group of lung conditions presents with higher eosinophil count $(>5 \%)$, with eosinophilic pneumonias having an even greater percentage of eosinophils present (>25\%). Idiopathic acute eosinophilic pneumonias (IAEP) can be subdivided into simple eosinophilic pneumonia (Loeffler's syndrome), chronic eosinophilic pneumonia and acute eosinophilic pneumonia (AEP). ${ }^{12}$

\section{CASE PRESENTATION}

A 44-year-old man, with a known case of chronic asthma since childhood was referred to the accident and emergency (A\&E) department from a primary healthcare centre (PHC) in view of a 3-week history of coryzal symptoms, cough productive of whitish sputum and shortness of breath despite treatment at the PHC. On being asked about his medical history, he stated that he had never smoked. The symptoms started 2 days after his arrival in England for a bird-hunting trip. While in England, he visited a general practitioner (GP) and started on amoxicillin $500 \mathrm{mg}$ orally three times a day for 7 days. On returning to Malta, he visited his GP who changed the medicine to clarithromycin $500 \mathrm{mg}$ BD (twice daily) PO for 7 days. He was reviewed regularly by his GP, who referred him to the PHC for regular salbutamol $5 \mathrm{mg}$ and ipratropium bromide $500 \mathrm{mcg}$ nebulisers.

Prior to his referral to A\&E, he had already been given hydrocortisone $100 \mathrm{mg}$ intravenous bolus and had completed a 7-day course of clarithromycin $500 \mathrm{mg}$ BD PO. However, all this management resulted in only mild improvement. On examination at the $\mathrm{PHC}$ he had an $\mathrm{SpO} 2$ of $88 \%$ on room air before nebuliser treatment, a pulse of $90 \mathrm{bpm}$, blood pressure of $149 / 107 \mathrm{~mm} \mathrm{Hg}$, respiratory rate of $20-25 \mathrm{bpm}$, temperature of $36^{\circ} \mathrm{C}$ and blood glucose of $6.7 \mathrm{mmol} / \mathrm{L}$. Respiratory examination revealed decreased air entry and sparse, coarse crepitations and wheezing bilaterally. The rest of the clinical examination was normal.

The initial chest X-ray (CXR) showed symmetrical, bilateral perihilar airspace shadowed with peribronchial cuffing and bilateral increased reticular markings (figure 1). The initial differential diagnosis was that of acute exacerbation of asthma on a background community-acquired pneumonia (CAP)

On admission to the hospital he was treated with paracetamol $1 \mathrm{~g}$ intravenous bolus, clarithromycin $500 \mathrm{mg}$ intravenous bolus and amoxicillin $1 \mathrm{~g}$ intravenous bolus. The following investigations were done during his admission: full blood count (FBC) which showed an elevated white cell count (WCC) of $29.83 \times 10^{9} / \mathrm{L}$ (normal range (NR): 4.30 $11.40 \times 10^{9} / \mathrm{L}$ ), especially with respect to neutrophils $11.84 \times 10^{9} / \mathrm{L}(39.7 \%)\left(\mathrm{NR}: 2.10-7.20 \times 10^{9} / \mathrm{L}\right)$ and eosinophils $14.36 \times 10^{9} / \mathrm{L}$ (NR: $0.10-0.70 \times 10^{9} / \mathrm{L}$ ); C-reactive protein (CRP) was elevated at $73 \mathrm{mg} / \mathrm{L}$ (NR $0-5 \mathrm{mg} / \mathrm{L}$ ); serum Immunoglobulins (IgE: - 956+++ IU/ml (NR: 150-300 IU/ml)); renal profile, thyroid function test, erythrocyte sedimentation rate (100, but it was taken 9 days post admission), blood cultures for microscopy, cultures and sensitivities, antineutrophil cytoplasmic antibodies testing and anti-nuclear antibody were all within their normal ranges; HIV screen (negative); mycoplasma IgM antibody (not detected); sputum microscopy, culture and sensitivities, methicillin-resistant Staphylococcus aureus nasal swab and urine for Legionella and Streptococcus pneumonia antigens (no growth detected); respiratory screen (positive for $S$. aureus).

Despite being treated with intravenous antibiotics and remaining asymptomatic, his WCC continued to rise. On repeated FBC, it was noted that he had an unusually high level of eosinophils. Hence, a blood film was requested which confirmed the presence of multiple eosinophils. This was reported 


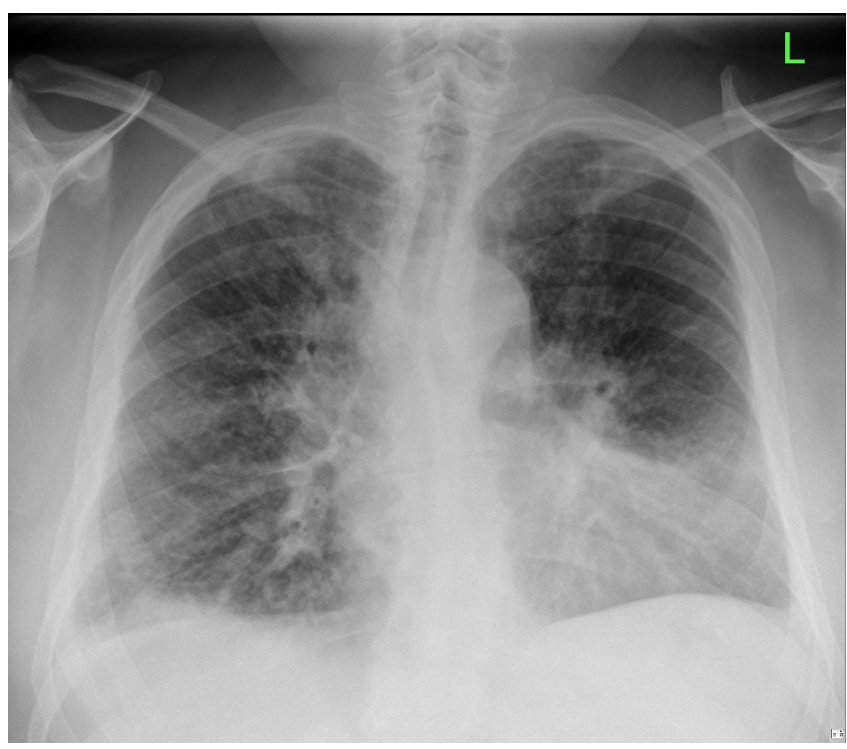

Figure 1 The chest X-ray showing symmetrical, bilateral perihilar airspace shadowed with peribronchial cuffing and bilateral increased reticular markings.

as follows: WC differential amended to reflect genuine eosinophilia that was not picked up by cell counters. For a few days, both neutrophil and eosinophil levels remained high. After 4 days of admission and receiving treatment, CXR was repeated and it showed no change in comparison to the CXR at presentation (figure 2).

As a result of the aforementioned findings from the investigations and clinical examinations carried out and the resistance to current management, a clinical diagnosis of AEP was suspected. The case was discussed with a consultant respiratory radiologist, who recommended a high resolution CT (HRCT) scan of the thorax. The HRCT, performed in full inspiration in prone position, showed small bilateral, symmetrical, pleural effusions, smooth interlobular septal thickening with upper lobe predominance (figure 3), airspace consolidation most evident in the left middle zone (figure 4), patches of ground-glass change (figure 5),

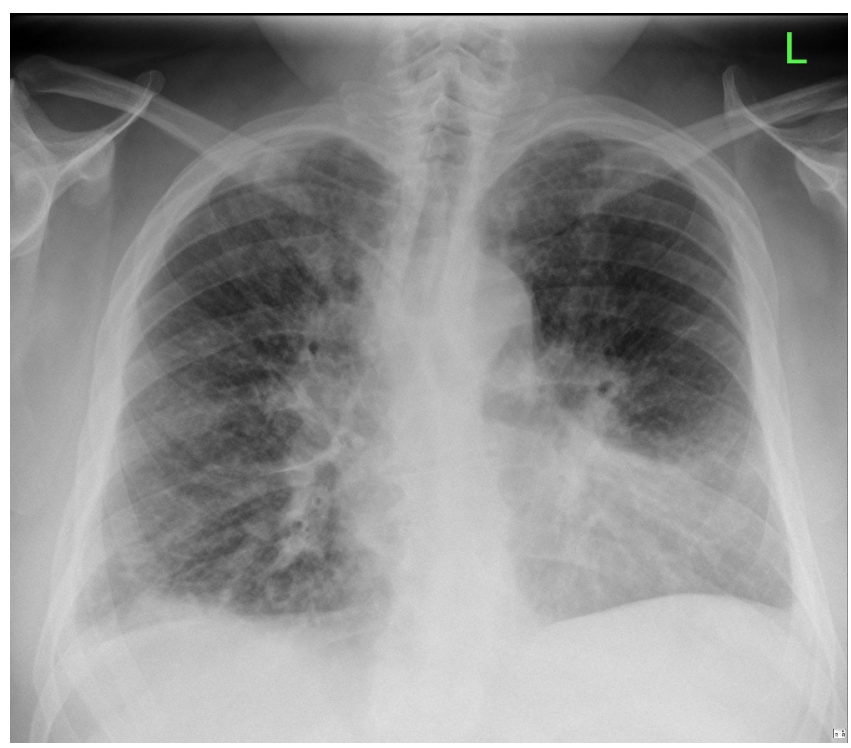

Figure 2 Repeated chest X-ray (CXR) showing no interval changes from initial CXR.

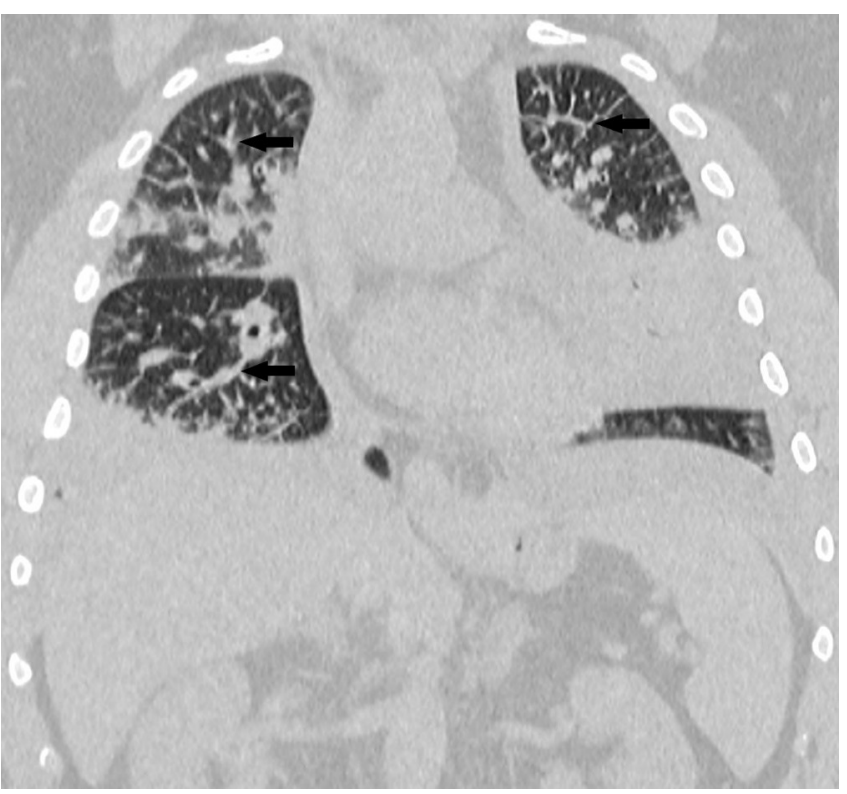

Figure 3 High resolution CT coronal view showing smooth interlobular septal thickening (arrows).

as well as thickening of the central perihilar and peribronchovascular soft tissue.t (figure 6).

The case was discussed in a multidisciplinary pulmonary (MDT) meeting and it was suggested that the diagnosis was possibly AEP. Bronchoscopy with BAL was needed to confirm the diagnosis. Bronchoscopy showed normal respiratory tract mucosa. BAL showed marked eosinophilia (68\%) which confirmed the diagnosis of AEP. Antibiotics and nebulizers were stopped and the patient was started on oral prednisolone $60 \mathrm{mg}$ daily.

\section{OUTCOME AND FOLLOW-UP}

The final diagnosis was AEP. The patient was discharged on his usual asthma medication and oral prednisolone $60 \mathrm{mg}$ daily for 2 weeks to be reduced by $5 \mathrm{mg}$ every alternate day and eventually stopped, along with oral omeprazole $20 \mathrm{mg}$ daily (until

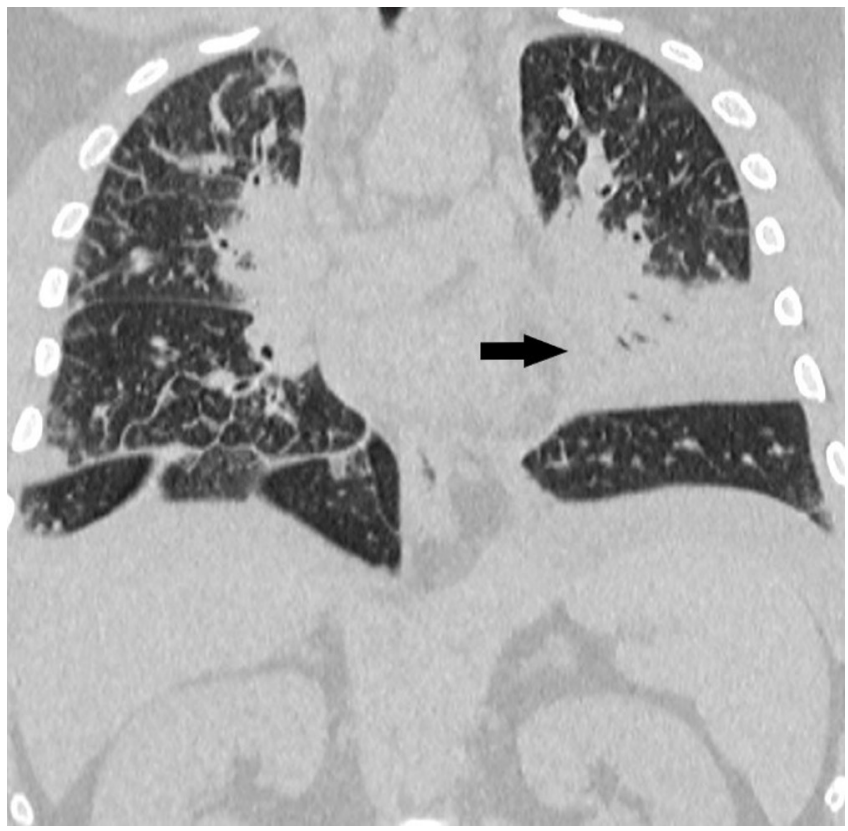

Figure 4 Airspace consolidation most evident in the left middle zone. 


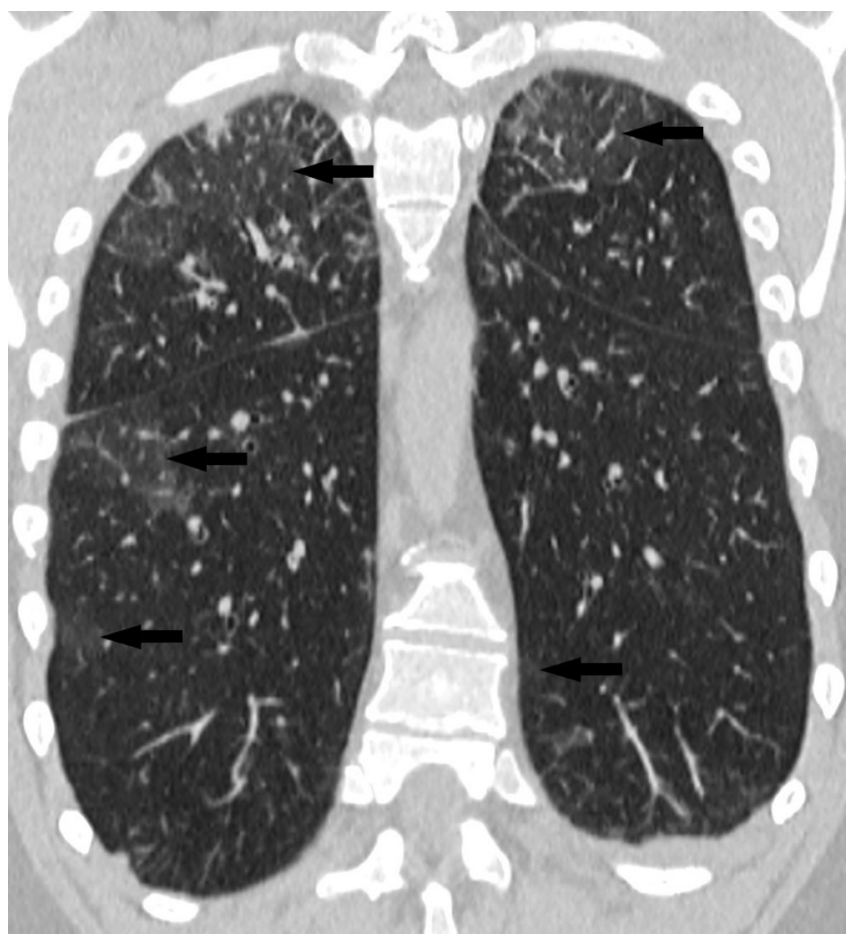

Figure 5 Patches of ground-glass change,

he finished the steroid course). He was given an outpatient follow-up visit 4 weeks later.

When reviewed at the outpatient department, he had just finished his oral steroid course. He was clinically asymptomatic and had no positive findings on clinical examination. CXR and FBC were repeated and pulmonary function tests (PFTs) were carried out. CXR showed complete resolution of the previous findings figure 7. The FBC normalised and PFTs showed no restrictive or obstructive abnormalities. With regard to his chronic asthma, he was started on inhaled fluticasone propionate $250 \mathrm{mg}$ daily, with a plan to decrease the dose if asthma was well controlled at the next outpatient visit. Additionally, a sleep study was booked in view of

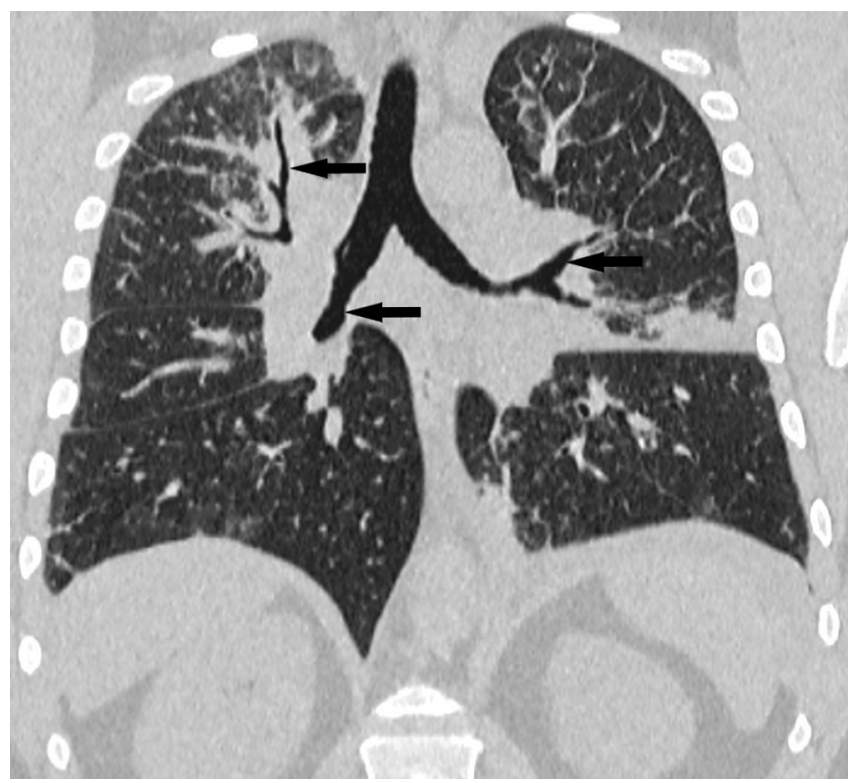

Figure 6 High resolution CT coronal view showing peribronchovascular soft tissue thickening (arrows).

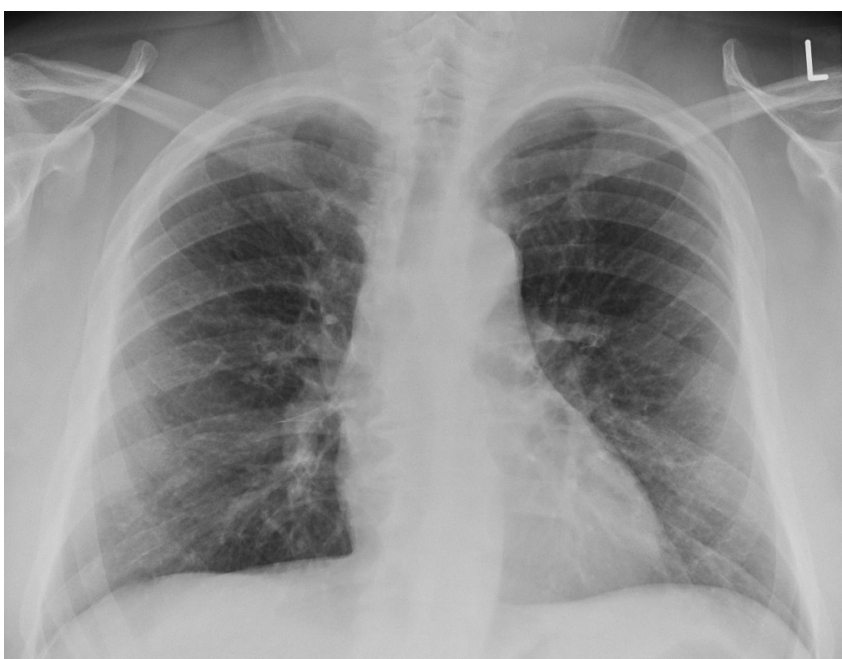

Figure 7 The chest X-ray showing complete resolution of the previous findings.

the possibility that the patient might be suffering from obstructive sleep apnoea in view of his obese habitus and snoring. He was followed up to monitor his progress.

\section{DISCUSSION}

The patient initially presented as a CAP which was unresponsive to amoxicillin (a penicillin) in the UK. Therefore, the second doctor, who saw him in Malta, decided to change his antibiotics to clarithromycin (a macrolide) in order to cover for a possible atypical pneumonia, especially in view of his recent travel to the UK which would put him at risk of Legionnaire's disease.

There was also the possibility of some form of psittacosis which can, rarely, infect humans and cause similar symptoms. Unsurprisingly, since he was an asthmatic, he developed wheezing during his infection. Asthma exacerbations are often precipitated by infections. He initially improved because he was given intravenous hydrocortisone as part of treatment for acute asthma exacerbation. This would also treat his eosinophilic pneumonia and explains his initial response to treatment.

The differential diagnoses of his CXR, apart from CAP, could also have been non-cardiogenic pulmonary oedema as he had bilateral increased reticular markings and small bilateral pleural effusions; however, there was nothing in his history to suggest this diagnosis and he had no prior cardiac history to suggest a cardiac cause.

CRP was only moderately elevated at 73 . In most cases of infective pneumonia, CRP is usually more than 100; hence this was a clue that the aetiology might not be infective. High serum IgE can be caused by allergies, infections and rare immune conditions such as hyper IgE syndrome but the patient did not have recurrent skin abscesses or pneumatocoeles on his CXR to suggest this diagnosis. IgE was most likely elevated due to his history of asthma and there was nothing to suggest a parasitic cause from his history or travel and no red flag symptoms to suggest malignancy. The fact that all his cultures and infectious screens were negative is further in keeping with an inflammatory cause rather than an infective one. The respiratory screen, being positive for $S$. aureus, was misleading in this case since there was no other evidence of S.aureus infection elsewhere. Retrospectively, the diagnosis of IAEP could have been made earlier had we noticed the elevated eosinophil count and acted on it. In fact, the diagnosis was brought up during the MDT pulmonary 
meeting, which highlights the importance of discussing complicated cases, both with other respiratory physicians and radiologists.

IAEP is a rare disease (less than 200 reported cases worldwide), first described in 1989, and is caused by eosinophilic pneumonia of undetermined aetiology. IAEP is characterised by a large number of eosinophil infiltration in the interstitium and air space, with rapid progression to acute respiratory failure. Patients present acutely with febrile, hypoxic respiratory failure associated with diffuse radiographic infiltrates and pulmonary eosinophilia, but without an underlying concurring allergy or infection. It affects men more than women and with an average age of 29 years, the range being 15 to 86 years. ${ }^{3}$ Patients who had just started smoking were more likely to develop AEP. ${ }^{45}$ AEP can also be due to an underlying infection caused by bacteria, virus, fungi or as a result of toxic inhalation. ${ }^{6}$

During the course of AEP, peripheral eosinophil count (PEC) tends to increase, and an initially elevated PEC is associated with a milder version of the disease. ${ }^{7}$ Interleukin-5 is an integral cytokine involved in the recruitment of eosinophils from peripheral blood into the lungs and the initial high levels of PEC result in a state of resolving inflammation. ${ }^{8}$ Mast cells are also involved in the inflammatory process of AEP. ${ }^{9}$

All patients present with a non-productive cough, dyspnoea and tachycardia. Most patients are usually healthy just prior to the onset of IAEP. The symptoms usually develop very rapidly within 1 to 7 days. ${ }^{10}$ The diagnostic criteria for IAEP include acute onset of febrile illness ( $<7$ days), diffuse bilateral pulmonary infiltrates, severe hypoxaemic respiratory failure (oxygen saturation $<90 \%$ on pulse oximetry or $\mathrm{PaO}_{2}<60 \mathrm{~mm} \mathrm{Hg}$ on room air), lung eosinophilia (BAL fluid eosinophilia of more than 25\%) and no known causes of acute eosinophilic lung disease (recent onset smoking or exposure to inhaled dust). ${ }^{11}$ CXRs show diffuse bilateral infiltrates, air space opacities, interstitial reticulonodular densities and/

Learning points

The case highlights the importance of recognising severe eosinophilia. In general asthmatics may have elevated eosinophil levels but not to this level. Usually asthmatics with eosinophilia are seen in association with sinus disease, nasal polyps and occasional aspirin exacerbated respiratory disease. (up to date)

- The case demonstrates the importance of reassessing the initial diagnosis when the patient fails to respond to initial treatment.

- Chest Xray (CXR) in asthmatic patients is usually normal or at most shows hyper inflated lung fields. Therefore, if CXR is abnormal, secondary causes have to be excluded.

- The case shows the importance of discussing the case in a multidiscipliinary pulmonary meeting with radiologists.

- Another clue was that C-reactive protein (CRP) is usually above $100 \mathrm{mg} / \mathrm{L}$ in bacterial pneumonia. Therefore, his low CRP suggested it may be a non-infective cause, that is, inflammatory. or pleural effusion. ${ }^{12} 13$ CT scans show diffuse areas of ground glass attenuation, airspace shadowing, poorly defined nodules and interlobar septal thickening. ${ }^{14} 15$

Management is usually achieved with intravenous corticosteroid therapy given for two to twelve weeks followed by oral use. ${ }^{16}$ Patients generally respond rapidly to steroids within the first week. ${ }^{17}$ Some patients may spontaneously recover. ${ }^{18}$ Very rarely does death occur in spite of steroid treatment. In patients who are not treated optimally, respiratory failure can occur, with such patients requiring mechanical ventilation.

Prognosis of IAEP is excellent with immediate diagnosis and prompt treatment. ${ }^{19}$ Delay in diagnosis and subsequent treatment may lead to mortality. The disease does not recur once treated properly. ${ }^{19}$

Contributors MP wrote the background, case summary, discussion and references. MS wrote the case presentation, outcome and follow-up. BCM reviewed the report. AM provided the images.

Funding The authors have not declared a specific grant for this research from any funding agency in the public, commercial or not-for-profit sectors.

Competing interests None declared.

Patient consent for publication Obtained.

Provenance and peer review Not commissioned; externally peer reviewed.

\section{REFERENCES}

1 Sohn JW. Acute eosinophilic pneumonia. Tuberc Respir Dis 2013;74:51-5.

2 Badesch DB, King TE, Schwarz MI. Acute eosinophilic pneumonia: a hypersensitivity phenomenon? Am Rev Respir Dis 1989;139:249-52.

3 Hayakawa H, Sato A, Toyoshima M, et al. A clinical study of idiopathic eosinophilic pneumonia. Chest 1994;105:1462-6.

4 Shintani H, Fujimura M, Ishiura Y, et al. A case of cigarette smoking-induced acute eosinophilic pneumonia showing tolerance. Chest 2000;117:277-9.

5 Fayyaz B. Acute eosinophilic pneumonia associated with smoking: a case report. J Community Hosp Intern Med Perspect 2018;8:119-22.

6 Philit F, Etienne-Mastroïanni B, Parrot A, et al. Idiopathic acute eosinophilic pneumonia: a study of 22 patients. Am J Respir Crit Care Med 2002;166:1235-9.

7 De Giacomi F, Decker PA, Vassallo R, et al. Acute Eosinophilic Pneumonia: Correlation of Clinical Characteristics With Underlying Cause. Chest 2017;152:379.

8 Jhun BW, Kim SJ, Kim K, et al. Clinical implications of initial peripheral eosinophilia in acute eosinophilic pneumonia. Respirology 2014;19:1059-65.

9 Jhun BW, Kim SJ, Kim K, et al. Clinical implications of correlation between peripheral eosinophil count and serum levels of IL-5 and tryptase in acute eosinophilic pneumonia. Respir Med 2014;108:1655-62.

10 Pope-Harman AL, Davis WB, Allen ED, et al. Acute eosinophilic pneumonia. A summary of 15 cases and review of the literature. Medicine 1996;75:334-42.

11 Janz DR, O'Neal HR, Ely EW. Acute eosinophilic pneumonia: A case report and review of the literature. Crit Care Med 2009;37:1470-4.

12 King MA, Pope-Harman AL, Allen JN, et al. Acute eosinophilic pneumonia: radiologic and clinical features. Radiology 1997;203:715-9.

13 Mochimaru H, Fukuda Y, Azuma A, et al. Reconsideration of discrepancies between clinical and histopathological features in acute eosinophilic pneumonia. Sarcoidosis Vasc Diffuse Lung Dis 2015:31:325.

14 Johkoh T, Müller NL, Akira M, et al. Eosinophilic lung diseases: diagnostic accuracy of thin-section CT in 111 patients. Radiology 2000;216:773-80.

15 Jeong YJ, Kim KI, Seo IJ, et al. Eosinophilic lung diseases: a clinical, radiologic, and pathologic overview. Radiographics 2007;27:617-37.

16 Rhee CK, Min KH, Yim NY, et al. Clinical characteristics and corticosteroid treatment of acute eosinophilic pneumonia. Eur Respir J 2013;41:402-9.

17 Natarajan A, Shah P, Mirrakhimov AE, et al. Eosinophilic pneumonia associated with concomitant cigarette and marijuana smoking. BMJ Case Rep 2013;2013. bcr 2013009001.

18 Allen JN, Pacht ER, Gadek JE, et al. Acute eosinophilic pneumonia as a reversible cause of noninfectious respiratory failure. N Engl J Med 1989:321:569-74.

19 Allen J. Acute eosinophilic pneumonia. Semin Respir Crit Care Med 2006;27:142-7. 
Copyright 2019 BMJ Publishing Group. All rights reserved. For permission to reuse any of this content visit https://www.bmj.com/company/products-services/rights-and-licensing/permissions/

BMJ Case Report Fellows may re-use this article for personal use and teaching without any further permission.

Become a Fellow of BMJ Case Reports today and you can:

- Submit as many cases as you like

- Enjoy fast sympathetic peer review and rapid publication of accepted articles

Access all the published articles

- Re-use any of the published material for personal use and teaching without further permission

Customer Service

If you have any further queries about your subscription, please contact our customer services team on +44 (0) 2071111105 or via email at support@bmj.com.

Visit casereports.bmj.com for more articles like this and to become a Fellow 